\title{
Seni Islam sebagai Media Dakwah \\ (Studi Kasus: Kesenian Tari Badui di Dusun Semampir, Desa Tambakrejo, Kecamatan Tempel, Kabupaten Sleman, Yogyakarta)
}

\author{
Nur Aminah Nasution \\ Mahasiswa Jurusan Sejarah Kebudayaan Islam, Fakultas Interdiciplinary \\ Islamic Studies, Program Pascasarjana, UIN Sunan Kalijaga Yogyakarta.
}

\begin{abstract}
This research examines about Islamic art (the art of dancing the Bedouin Village of Semampir) as a media of religious proselytizing. This theme is considered to be important, considering one of the efferts in delivering media of religious proselytizing of Islam is through art. As always practiced by Wali Songo in Java, with the use of various arts for this media of religious proselytizing of Islam. This study is besed of field research against Bedouin dance arts in the Village of Semampir. The primary source is the result of interviews with people involved with this study and other writings that are relevant. Results of the study show that this simple Bedouin dance art is really a media propaganda for the community of the Village of Semampir in particular and society in General. Factually, this art has renewed the knowledge society, which was not previously so religious practices in response to the group, as well as add to the scientific vocabulary for readers in General and especially writers. Side of Islam is in the art of dances at the Bedouin poetries while performing. The poetries are divided into two languages, namely Arabic and Indonesian, Arabic poetry taken from the book of Arabic Verse Barzanji and Indonesian poetry contains the opening and closing greetings. As for the movements of the dencer describes a group of people practicing war, as it has always been practiced by Bedouin Arabs. Keywords: Islamic Art, Art Dance Bedouin Village of Semampir, Media of Religious Proselytizing.
\end{abstract}

\section{PENDAHULUAN}

Dalam kitab Kifâyah al-Atqiyâa' dijelaskan bahwa manusia adalah hewan yang berfikir (Hayawân an-Nâtiq) yang mempunyai banyak keinginan dan bakat. Salah satu yang ingin dikembangkan manusia ialah bidang seni. Seni adalah hasil dan bakat manusia, manusia dan kesenian tidak dapat dipisahkan, sebab kesenian merupakan perwujudan dari gagasan dan perasaan seseorang yang tidak pernah lepas dari masyarakat 
dan dibesarkan melalui kebudayaan. ${ }^{1}$ Bahkan sebelum manusia mengenal tulisan, seni telah menjadi salah satu bagian dalam kehidupan mereka. ${ }^{2}$

Ada berbagai macam seni yang kita kenal, seperti ada yang berbentuk tulisan, kaligrafi (lukisan), ukir, sastra, seni wayang, seni rupa, tari, dan lain sebagainya. Lebih lanjut tari juga bermacam ragam, setiap daerah memiliki tari masing-masing untuk menyampaikan nilai-nilai budaya yang ada di masyarakat tertentu. Ada beberapa jenis tari yang di dalamnya mengandung nilai-nilai ajaran Islam, salah satunya adalah tari Badui. Tari Badui merupakan kesenian tradisional yang bersifat kerakyatan atau disebut sebagai suatu seni pertunjukan rakyat. Tari Badui termasuk kesenian yang bernafaskan Islam dan termasuk ke dalam jenis shalawatan. ${ }^{3}$ Selain itu juga dapat dikategorikan sebagai media dakwah.

Secara historis, awal keberadaan tari Badui di Indonesia diprakarsai oleh seorang seniman yang berasal dari Desa Mendut, yang kala itu sedang menjalankan ibadah haji ke tanah suci Mekkah. Ketika di Mekkah, ia melihat dan sangat tertarik dengan salah satu tarian yang dikembangkan oleh suku Badui. Berawal dari rasa ketertarikan itulah lalu ia belajar tari Badui. Agar tarian tersebut tetap bisa dinikmati maka sepulang dari Mekkah ia lalu mengembangkan kesenian tari Badui tersebut di tanah air (Indonesia).

Di Indonesia kesenian tari Badui pertama kali berkembang di Karesidenan Kedu, Jawa Tengah, tepatnya di daerah Blabak, Kabupaten Magelang. Kesenian tari Badui ini sangat menarik karena memperlihatkan gerakan-gerakan yang enerjik, keras, dan dinamis. Oleh karenanya, wajarlah kalau pada waktu itu banyak sekali orang yang tertarik untuk mempelajarinya, dan selanjutnya berusaha mengajarkan dan menyebarluaskannya ke daerah masing-masing. Adapun wilayah penyebarannya sampai di Dusun Cempan, Desa Jero Agung, Kecamatan Srumbung, Kabupaten Magelang, lalu Desa Kricaan, Kecamatan Salam, Kabupaten Magelang, dan Dusun Nglengkong, Desa Sumberrejo, Kecamatan Tempel, Kabupaten Sleman.

Setelah berkembang di Dusun Nglengkong, tari Badui ini dikembangkan oleh empat orang warga Dusun Semampir yaitu Sulistiyo, Abdul Basyar, Jadi, dan R. Muhadi. Mereka mempelajari tari Badui dari para pelatihnya yang berasal dari Dusun Nglengkong, yaitu Idris, Ansori, Munasrip, dan Amriyah. Hal itu dilakukan setiap malam Minggu selama lebih kurang satu tahun (1960). Setelah itu, Sulistiyo dan Abdul Basyar

1 Koentjaraningrat. Pengantar Ilmu Antropologi Budaya (Jakarta: Aksara Baru, 1985), h. 204.

2 Dick Hartoko. Manusia dan Seni (Yogyakarta: Kanisius, 1984), h. 21.

3 Agus Salim. "Tari Badui di Dusun Semampir, Takbakrejo, Tempel, Sleman." (Skripsi, 2004), h. 23. 
kemudian mengajarkannya kepada pemuda-pemuda di Dusun Semampir setiap malam Jum'at. ${ }^{4}$

Studi ini berfokus pada tari Badui yang ada di Dusun Semampir, Desa Tambakrejo, Kecamatan Tempel, Kabupaten Sleman. Menurut sejarahnya, tari Badui di Dusun Semampir sudah ada sejak tahun 1960 yang waktu itu hanya berfungsi sebagai media dakwah saja. Dikatakan demikian karena di dalamnya ada perpaduan unsur tari dan nyanyian Qasidah berbahasa Arab dan Indonesia yang berfungsi untuk menyampaikan pesan-pesan pendidikan dan nilai-nilai Islam.

Tari Badui ditampilkan pada saat ada acara pengajian. Hal ini dimaksudkan sebagai sarana untuk mengumpulkan peserta pengajian. Pada acara pengajian tersebut, tari Badui ditampilkan dua kali. Penampilan yang pertama, sebelum dimulainya pengajian dengan tujuan agar peserta pengajian datangnya lebih awal sehingga tidak terlambat dalam mengikuti pengajian. Sedangkan penampilan yang kedua, sebelum pengajian selesai dengan maksud agar peserta pengajian tidak pulang sebelum acara pengajian selesai. Dengan demikian, tari Badui erat kaitannya dengan dakwah Islam di dusun tersebut.

Tahun 1961 merupakan titik awal perkembangan kesenian tari Badui yang saat itu tidak hanya berfungsi sebagai sarana dakwah saja, melainkan juga mulai berfungsi sebagai media hiburan (pertunjukan di luar acara pengajian), misalnya dalam acara pernikahan dan peringatan hari kemerdekaan Indonesia dengan tujuan untuk menghibur masyarakat. Sampai pada tahun 1965, tari Badui mengalami perkembangan yang sangat signifikan. Salah satu buktinya adalah mereka sering diundang dalam acara pernikahan ke luar Dusun Semampir. Sementara itu pada tahun 1965-1976, kesenian tari Badui sempat mengalami kevakuman, yang berarti tidak ada kegiatan sama sekali.

Kevakuman tari Badui tersebut mengakibatkan praktik keagamaan di tengah-tengah masyarakat setempat menjadi menurun. Hal itu terjadi dalam waktu yang relatif lama, padahal sebelumnya dirintis dengan menghabiskan tenaga yang cukup banyak, di antaranya mencari orangorang yang berbakat dalam seni tari, kemudian melatihnya hingga mereka mampu merealisasikannya. Faktor utama yang melatarbelakangi terjadinya kevakuman tersebut adalah situasi nasional yang tidak kondusif pada periode pemberontakan G30 S/PKI pada tahun 1965. Tari Badui bisa bangkit kembali pada tahun 1977 sampai sekarang. Pada awal masa kebangkitannya, tari Badui telah banyak mengalami perubahanperubahan terutama dalam hal aktivitas pertunjukan mereka yang semakin banyak sehingga menjadi populer. Tari Badui kian, dikenal mulai

4 (Wawancara dengan bapak Sutarman, pemain musik tahun 1960-an. Selasa, 13 Januari 2015, pukul 15:30 WIB). 
dari tingkat lokal sampai tingkat nasional. Walaupun tari Badui ini memiliki fungsi sebagai media dakwah dan media hihuran, tetapi dalam tulisan ini pembahasan lebih difokuskan sebagai media dakwahnya saja.

\section{HASIL DAN PEMBAHASAN}

\section{Sejarah Seni Islam}

Islam sebenarnya menghidupkan rasa keindahan dan mendukung kesenian, namun dengan syarat-syarat tertentu, yakni jika kesenian itu membawa perbaikan dan tidak merusak atau menghancurkan, tetapi membangun. Pada masa kejayaan peradabannya, Islam telah menghidupkan bermacam-macam seni yang berkembang dan berbeda dengan produk-produk peradaban lainnya seperti seni kaligrafi, dekorasi, dan seni ukiran di biasanya terdapat di masjid-masjid, di gedung-gedung, di pedang, bejana-bejana perak, pada kayu, keramik, dan lain sebagainya.

Selanjutnya, Islam juga menaruh perhatian besar pada seni sastra, terutama oleh bangsa Arab. Mereka berkarya dengan apa yang mereka pelajari dari bangsa-bangsa lain. Kemudian datanglah al-Qur'an yang memberi nilai sastrawi. Misalnya, membaca dan mendengarkan al-Qur'an bagi orang yang mengerti dan berfikir merupakan santapan ruhani dan makanan jiwa yang tidak dapat dibandingkan dengan santapan yang lain. Ini bukan hanya karena kandungnnya saja, tetapi juga karena metode penyajiannya, termasuk lagu, tajwid, dan aspek estetik yang menyertainya hingga menyebabkan telinga mendengarkan dan hati bergetar, terutama jika yang membacanya adalah orang yang memiliki suara yang indah. ${ }^{5}$

\section{Definisi Seni Islam}

Islam merupakan agama tauhid, yang berarti intisari ajaran Islam sekaligus esensi seluruh ajaran Islam. Al-Faruqi menyatakan "There can be no doubt that essence of Islamic civilication is Islam; or that essence of Islam is tauhid". Artinya, dapat dipastikan bahwa esensi dari seluruh peradaban Islam adalah Islam, dan esensi dari Islam adalah tauhid. Hal ini menunjukkan bahwa kesenian dalam Islam harus selaras dengan nilainilai tauhid. Kalimat tauhid yang paling singkat, tetapi memiliki makna yang sangat dalam yakni "Laa Ilaaha Illa Allah." Inti kalimat ini adalah membebaskan manusia dari ketundukan terhadap selain Allah SWT., dan untuk menyembah Allah SWT., semata (Tahrir al-Nas 'Ibad Ila Ibaditillah). Jadi, berkesenian harus mencerminkan semangat pembebasan tersebut, bukan sebaliknya. Oleh karena itu, kesenian dalam Islam bukan hanya

${ }^{5}$ Yusuf Al-Qardhawi. Islam dan Seni (Bandung: Pustaka Hidayah, 2000), h. 11-12. 
sekedar mengajarkan moral, tetapi harus mengandung moral. Artinya, untuk menyampaikan pesan-pesan moral melalui kesenian, harus tetap dalam koridor moral.

Seni Islam merupakan hasil dari pengejewantahan keesaan dalam bidang keanekaragaman. Ia harus merefleksikan kandungan prinsif keesaan Ilahi. Seni Islam harus mewujudkan, dalam taraf fisik yang secara langsung dapat dipahami oleh fikiran yang sehat, realitas-realitas dasar dan perbuatan-perbuatan sebagai tangga bagi pendakian jiwa dari yang dapat dilihat dan didengar menuju yang ghaib. Ada beberapa norma yang harus dipegang dalam kesenian menurut Islam, yaitu:

1) Dilarang melukis lukisan yang bersifat pornografi, serta melukis hal-hal yang bernyawa.

2) Dilarang menciptakan hikayat yang menceritakan dewa-dewa, kebiasaan pengarang yang mengkritik Tuhan.

3) Dilarang menyanyikan lagu-lagu yang berisikan kata-kata yang tidak sopan.

4) Dilarang memainkan musik yang merangsang kepada gerakangerakan sensual.

5) Dilarang berpeluk-pelukan antara laki-laki dan perempuan atas nama tarian.

6) Dilarang menampilkan drama dan film yang melukiskan kekerasan, kebencian, dan kekejaman.

7) Dilarang memakai pakaian yang memamerkan aurat. ${ }^{6}$

Seni secara sederhana adalah usaha untuk menciptakan bentukbentuk yang menyenangkan, bentuk-bentuk yang menyenangkan itu memuaskan penghayatan, dan penghayatan itu dapat dipuaskan manakala kita mampu mengapresiasinya. ${ }^{7}$ Ada berbagai macam bentuk seni sebagaiamana yang sudah dituliskan di atas yakni, seni tari, seni rupa, seni lukis, dan lain-lain. Seni tari dianggap bersifat Islami apabila pada kandungan pesan yang disampaikan saat menari mengandung unsur-unsur Islam. Dengan demikian unsur keislamannya bukan hanya semata-mata pada gaya atau tekniknya saja tetapi lebih pada pesan yang disampaikan pada tari Badui. ${ }^{8}$ Jadi, seni Islam adalah seni yang mengandung unsur-unsur keislaman yang terkandung didalam al-Qur'an dan al-Hadits.

${ }^{6}$ M. Asy'ari. "Islam dan Seni" Jurnal Hunafa (STAIN Palu) Vol. 4, No. 2 (Juni 2007), h. 171-172.

7 Sidi Gazalba. Pandangan Islam tentang Kesenian (Jakarta: Bulan Bintang, 1977), h. 20.

8 Saudi Berlian \& Jabrohim. Islam dan Kesenian (Yogyakarta: MKM UAD Lembaga Litbang PP Muhamadiyah, tanpa tahun), h. 117. 
Seni merupakan perkara yang sangat penting karena berhubungan dengan hati dan perasaan manusia. Seni berusaha kecenderungan dan perasaan-perasaan jiwa manusia dengan alat-alat yang beraneka ragam dengan menggunakan alat-alat yang dapat didengar, dibaca, dilihat, dirasakan, maupun dipikirkan. Karena seni merupakan alat untuk mencapai tujuan, maka hukumnya sejalan dengan hukum tujuannya. Artinya, kalau digunakan untuk tujuan yang positif, hukumnya halal, tetapi sebaliknya kalau digunakan untuk tujuan yang negatif, maka hukumnya haram.

\section{Kesenian Tari Badui di Dusun Semampir}

Nuansa Islam dalam tari Badui tampak ketika dalam tariannya, sang vokalis menyanyikan shalawat. Salah satunya shalawat yang mengkisahan riwayat hidup Nabi Muhammad SAW., dan para sahabatnya. Shalawatan - demikian disebut - adalah jenis pelembagaan tari yang bernafaskan keislaman. Dalam perkembangannya, tradisi shalawatan terdapat di beberapa daerah pedesaan yang mayoritas beragama Islam. ${ }^{9}$ Di Dusun Semampir, shalawatan dipadukan dalam syair kesenian khas tari Badui.

Kata shalawatan berasal dari bahasa Arab, bentuk jamak dari shalat, yang berarti do'a. Pelembagaan ini pada mulanya hanya merupakan bentuk seni membaca beberapa kitab Barzanji atau kitab Shalawat Badar. Kitab tersebut berupa do'a atau pujian terhadap Allah SAW., maupun Rasul-Nya, terutama dapat dilihat dari syair-syair, baik yang masih menggunakan bahasa Arab maupun bahasa Indonesia. Seni membaca kitab itu berkembang dan dihayati oleh masyarakat lingkungannya terutama di daerah-daerah pedesaan. Kepercayaan agama Islam sendiri, pelembagaan seni merupakan fitrah, karena umat Islam pasti membutuhkannya. Tujuan penyebaran agama Islam dengan melembagakan bentuk kesenian tidak menyimpang dari ajaran Islam itu sendiri.

Pelembagaan tari dan shalawat di masyarakat tradisional pedesaan berkembang dengan pesat dan bentuknya sangat unik. Kesenian itu menggabungkan seni musik, sastra, gerak, tari, dan gerak-gerak bela diri atau pencak silat. Contohnya di sekitar pedesaan Jawa Tengah dan Yogyakarta, terdapat bermacam-macam jenis kesenian yang kita kenal seperti tari Badui, Rodad, Kuntulan, Lengger, Angguk, Trengganon, Peksi Moi, Kobrasiswa, Dolalak, Modreng, dan Panjidor. ${ }^{10}$

${ }^{9}$ Suandiyo Hadi. Sosiologi Tari; Sebuah Telaah Kritis yang Mengulas Tari dari Zaman ke Zaman (Yogyakarta: Pustaka Pelajar, 2005), h. 58.

${ }^{10} \mathrm{Ibid}$. h. h8-59. 
Tari Badui mudah diterima oleh masyarakat Semampir karena mayoritas dari mereka adalah muslim. Sebuah peristiwa terkadang orang menganggapnya sebagai suatu hal yang tidak penting, sebagaimana yang terjadi pada kesenian tari Badui yang tidak diketahui secara utuh di Indonesia, terutama karena tidak ditemukan sumber tertulis yang membahas tentang hal itu. Namun, menurut keterangan tokoh masyarakat Dusun Semampir, tari Badui sebenarnya telah tumbuh di Dusun Semampir sejak tahun 1960.

Awal keberadaan tari Badui di Dusun Semampir diprakarsai oleh Sulistiyo dan Abdul Basyar. Pada tahun 1960, keduanya berlatih ke Dusun Nglengkong pada setiap malam Minggu yang ditemani oleh Jadi dan R. Muhadi. Setelah Sulistiyo dan Abdul Basyar merasa bisa, maka keduanya melatih pemuda-pemuda Dusun Semampir setiap malam Jum'at. Meski mereka melatih pemuda-pemuda pada malam Jum'at di Dusun Semampir, namun pada malam Minggu Sulistiyo, Abdul Basyar, Jadi, dan R. Muhadi tetap ikut berlatih di Dusun Ngelengkong. Jadi, antara belajar dan mengajarkannya dilaksanakan pada tahun yang sama.

Setelah pemuda-pemuda Dusun Semampir mahir, maka mereka langsung melakukan pertunjukan yang difungsikan untuk mengiringi pengajian. Adapun tujuannya adalah sebagai sarana dakwah. Seiring dengan berjalannya waktu maka pada tahun 1961 tari Badui ini mulai berkembang. Tari Badui tidak hanya berfungsi sebagai sarana dakwah saja, namun dalam perkembangannya pada tahun 1961-1965 juga berfungsi sebagai sarana hiburan. Selain dipertunjukkan pada acara pengajian,masyarakat Semampir juga memanfaatkannya untuk ditampilkan pada acara-acara pernikahan di Dusun Semampir tersebut.

Pada dasarnya anggota kesenian tari Badui juga merupakan peserta dari suatu kelompok pengajian. Dalam rangka peningkatan ilmu-ilmu agama dan realisasi dalam berdakwah, kesenian tari Badui mempunyai beberapa kegiatan yang menjadi program kerja kesenian tersebut, yaitu pengajian rutin dan peringatan hari-hari besar.

Penduduk Dusun Semampir mempunyai dua macam pengajian yang dilaksanakan oleh masyarakatnya, yakni pengajian pada malam Jum'at Kliwon dan pengajian pada acara hari-hari besar Islam. Tari Badui dipertunjukkan pada saat sebelum pengajian dimulai dengan maksud untuk mengumpulkan para peserta pengajian supaya tidak terlambat. Kemudian sebelum selesainya pengajian, tari Badui masih ditampilkan dengan tujuan supaya peserta pengajian tidak cepat-cepat pulang dan sebagai tanda bahwa pengajian akan selesai.

Sebagaimana keterangan dalam kitab Ta'limal-Muta'allim pada bab "Adab" dijelaskan bahwa menuntut ilmu dalam majelis-majelis ilmu, termasuk di tempat beribadah, sebaiknya tidak menyegerakan pulang, karena keberkahan ilmu yang didapat atau ke-maqbul-an do'a yang 
dipanjatkan tepat pada orang-orang yang menerimanya (ilmu) atau memintanya (do'a) dengan tenang. Pada saat akan tampil mereka meminjam kostum. Biaya peminjamannya diambil dari hasil infaq dari masyarakat Dusun Semampir itu sendiri.

Pada saat merayakan peringatan hari besar seperti Maulid Nabi, Isra' Mi'raj, Nuzulul Qur'an, dan lain sebagainya tari Badui selalu dipentaskan. Maulid Nabi adalah memperingati kelahiran Nabi Muhammad SAW. Sebagai cara umat Islam memperingatinya yaitu dengan mengadakan acara pengajian. Di Dusun Semampir itulah kesenian tari Badui juga dipertunjukkan kepada khalayak ramai yang mana dalam syair-syair tari Badui banyak menyangkut tentang kelahiran Nabi. Contohnya pada syair yang berjudul Mauludun Nabi, Limaulidi, dan lainlain (lihat Lampiran). Demikian pula pada peringatan Isra' Mi'raj dan Nuzulul Qur'an yang mempunyai arti dan peranan yang besar pada umat Islam. ${ }^{11}$ Di Dusun Semampir pada saat memperingati hari-hari besar, selain mendengarkan dakwah seorang ustadz juga menyaksikan kesenian tari Badui itu sendiri.

\section{PENUTUP}

Salah satu media dakwah dalam Islam adalah seni Islam, dan tari merupakan cabang seni Islam. Di Yogyakarta, tepatnya di Dusun Semampir, Desa Tambakrejo, Kecamatan Tempel, Kabupaten Sleman, terdapat seni tari Badui yang telah berkembang sejak tahun 1960. Model seperti itu telah dipraktikkan berabad-abad yang lalu pada zaman Wali Songo yang menggunakan seni dalam mendakwahkan ajaran Islam kepada masyarakat Jawa. Masyarakat pada umumnya dan masyarakat Dusun Semampir khususnya mengakui bahwa tari Badui merupakan media dakwah Islam. Sebab, kehadiran kesenian ini dapat menambah wawasan dan pengetahuan keislaman bagi masyarakat. Karena memang seni tari Badui ini merupakan seni yang bernafaskan Islam, jika dilihat dari syair-syair yang dinyanyikan di saat pertunjukan.

\section{DAFTAR PUSTAKA}

Al-Qardhawi, Yusuf. Islam dan Seni. Bandung: Pustaka Hidayah, 2000. Asy'ari, M. "Islam dan Seni." Jurnal Hunafa (STAIN Palu) Vol. 4, No. 2 (Juni 2007).

Cheema, Mahmud Ahmad. Isra' dan Mi'raj Nabi Muhammad SAW. Jemaat Ahmadiyah Indonesia, 1988.

11 Mahmud Ahmad Cheema. Isra' dan Mi'raj Nabi Muhammad SAW (Jemaat Ahmadiyah Indonesia, 1988), h. 1. 
Gazalba, Sidi. Pandangan Islam tentang Kesenian. Jakarta: Bulan Bintang, 1977.

Hadi, Suandiyo. Sosiologi Tari; Sebuah Telaah Kritis yang Mengulas Tari dari Zaman ke Zaman. Yogyakarta: Pustaka Pelajar, 2005.

Hartoko, Dick. Manusia dan Seni. Yogyakarta: Kanisius, 1984.

Koentjaraningrat. Pengantar Ilmu Antropologi Budaya. Jakarta: Aksara Baru, 1985.

Salim, Agus. "Tari Badui di Dusun Semampir, Takbakrejo, Tempel, Sleman." Skripsi, 2004.

Saudi Berlian \& Jabrohim. Islam dan Kesenian. Yogyakarta: MKM UAD Lembaga Litbang PP Muhamadiyah, tanpa tahun.

Wawancara dengan bapak Sutarman, pemain musik tahun 1960-an. Selasa, 13 Januari 2015, pukul 15:30 WIB, di rumah bapak Fauzan (Kepala Dukuh Dusun Semampir Wetan).

\section{LAMPIRAN}

1. Syair-syair dan gambar-gambar Kesenian Tari Badui Dusun Semampir

\section{a. Syair-syair Berbahasa Arab}

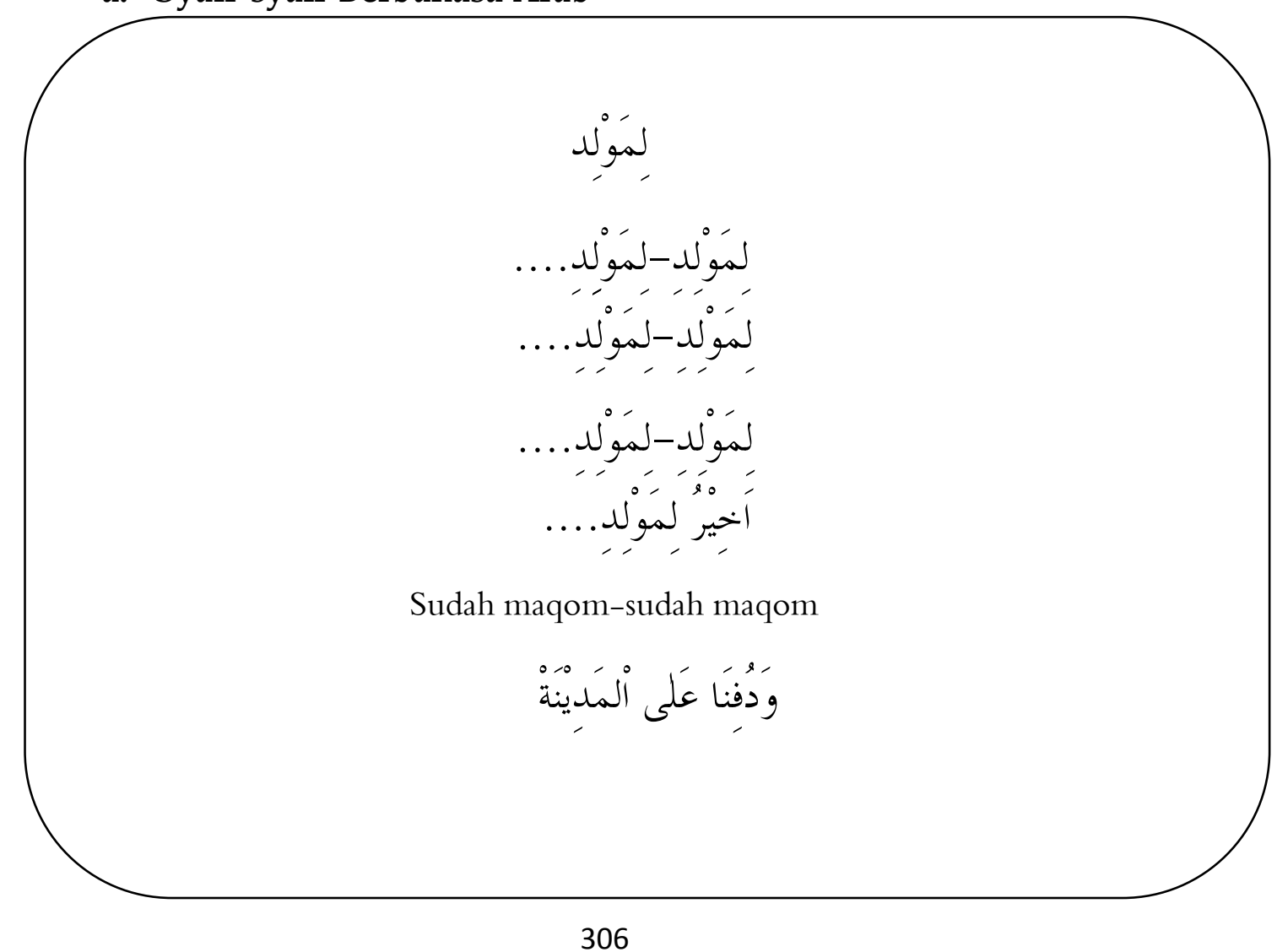




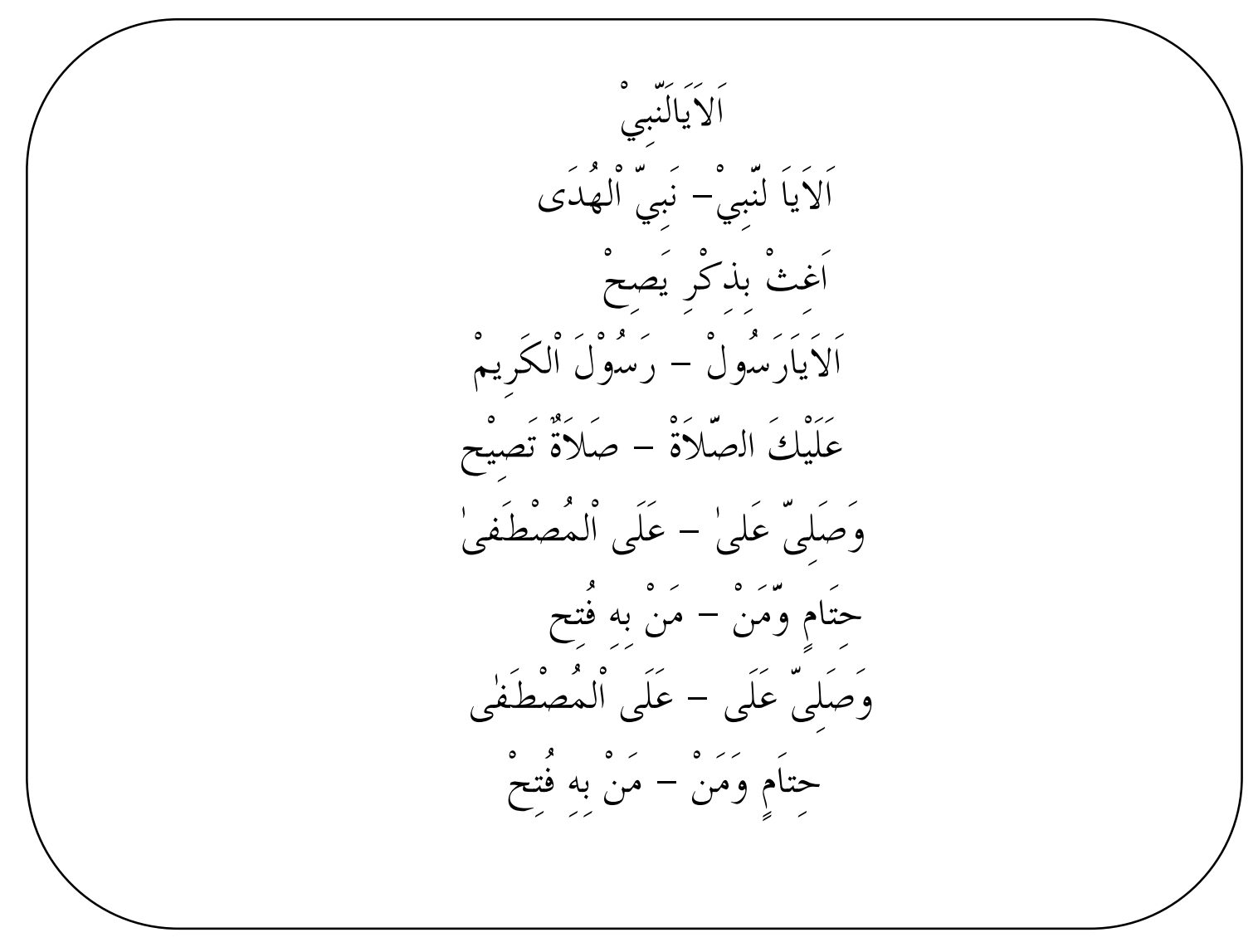




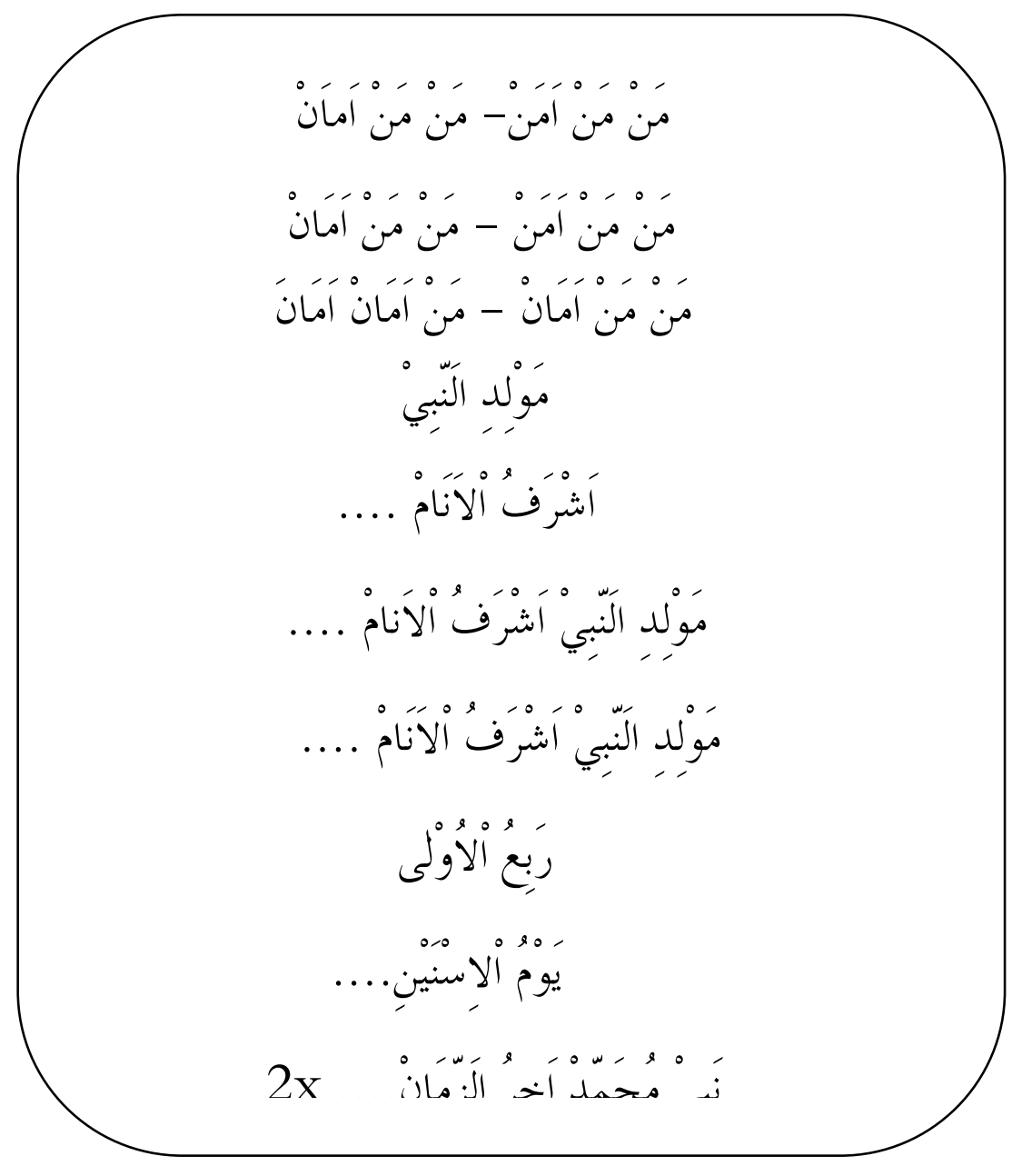

\section{b. Syair-syair Berbahasa Indonesia}

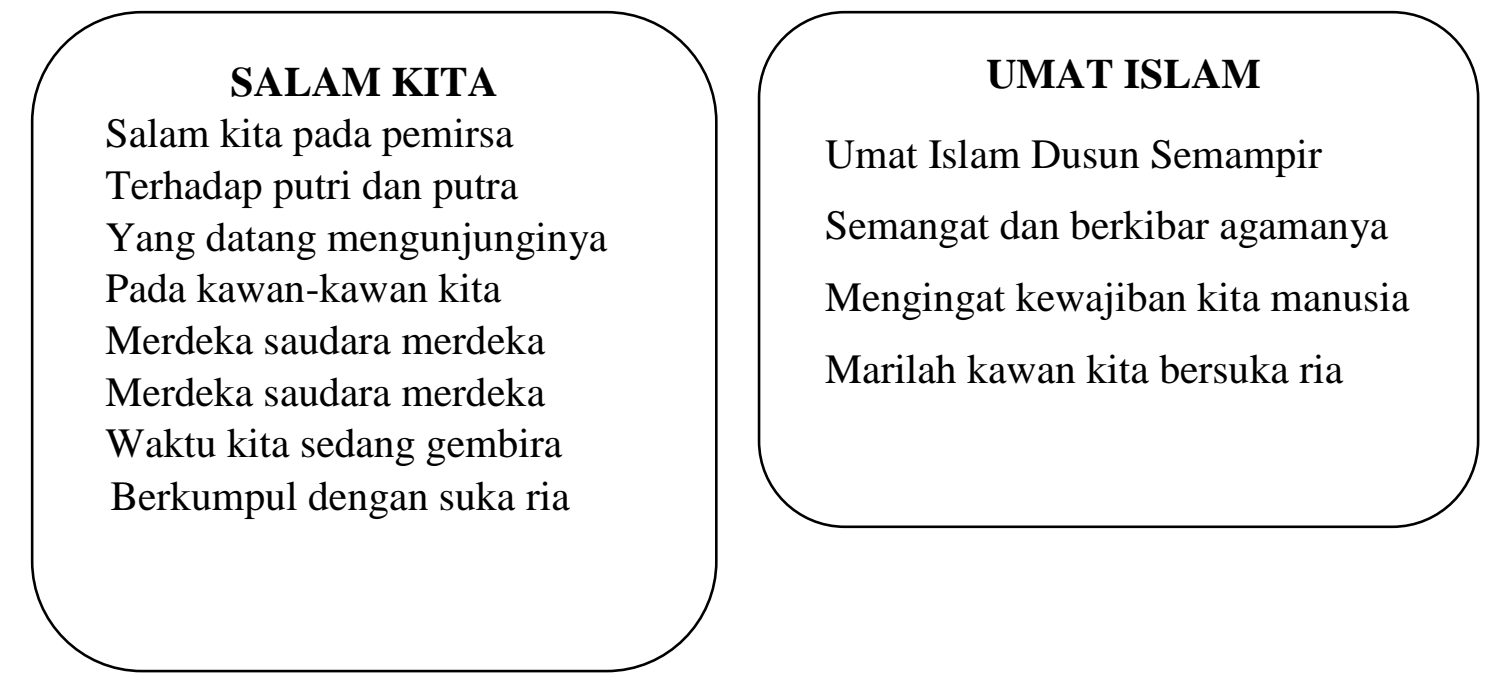




\section{WAHAI TEMAN}

Wahai teman-temanku sekalian

Wahai teman-temanku sekalian

Mari mengabdi kepada Tuhan

Mudah-mudahan Tuhan melindungi 2x

Dari segala godaan syaitoni

Yang meresap dalam hati sanubari

Dari segala godaan syaitoni

Yang meresap dalam hati sanubari

\section{TEGAK TERTIB}

Tegak dan tertib, tongkat badankakinya....

Tegak dan tertib, tongkat badankakinya....

Kiri-kanan berganti, pandangkanan-kiri.... 2x

Dengarkanlah, tanda berhenti tanda, sendu berbunyi.

\section{TERIMA KASIH}

Terima kaih kami ucapkan

Budi daya dan kebaikan

Tidak akan kami lupakan

Tuan-tuan semua....

Datang beserta pulang.

\section{MARILAH KAWAN}

Marilah kawan gerakkan Islam

Untuk mengisi kemerdekaan....

Negara kita Indonesia

Kekal abadi nusa dan bangsa

Dapat mengatur sakti dan jujur

Rakyat semua menjadi makmur

Subhanul muslimin tegak dan rajin

Gerakkan Islam turut menjamin

Wahai saudara kita muslimin

Sekian kututup ku-ucapkan

Amin...

Merdeka-merdeka....

Sekali tetap merdeka....!

\section{LE}

Lekas main di tempat ini

Sungguh kami datang di tempat ini

Lekas main di tempat ini

Sungguh kami datang di tempat ini

Pukul delapan kami mulai

Pukul delapan kami mulai

Setengah satu baru berhenti

Setengah satu baru berhenti

Habis permainan di tempat ini. 
c. Grup kesenian tari Badui Dusun Semampir saat pertunjukan

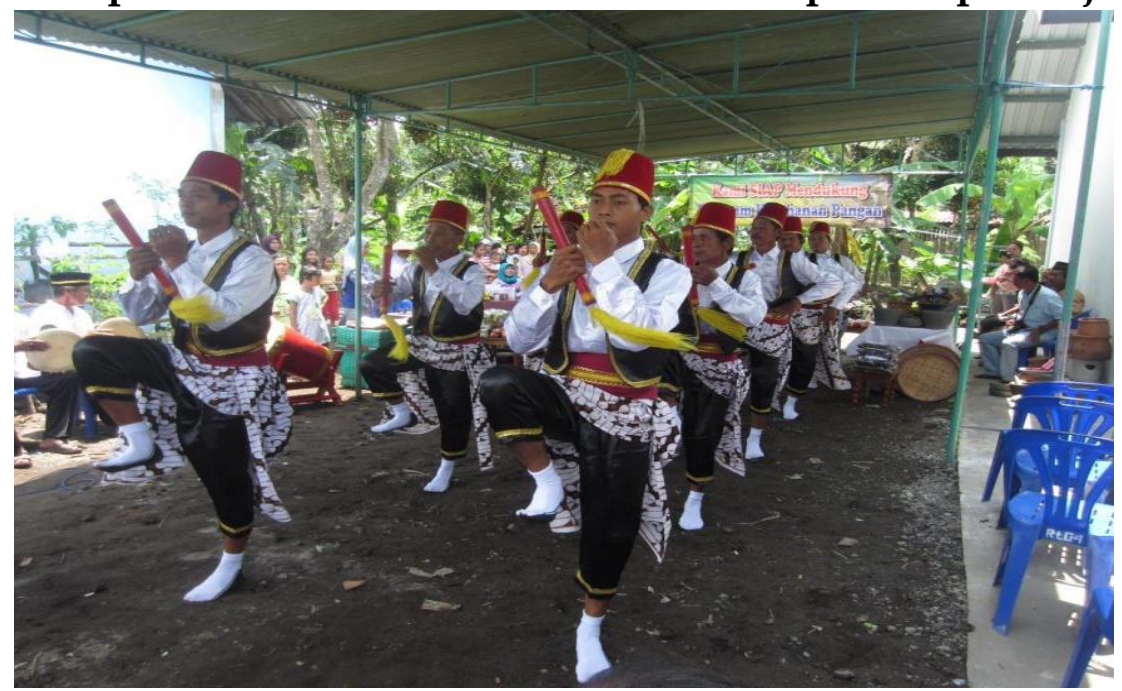

Sumber: Dokumentasi Pribadi
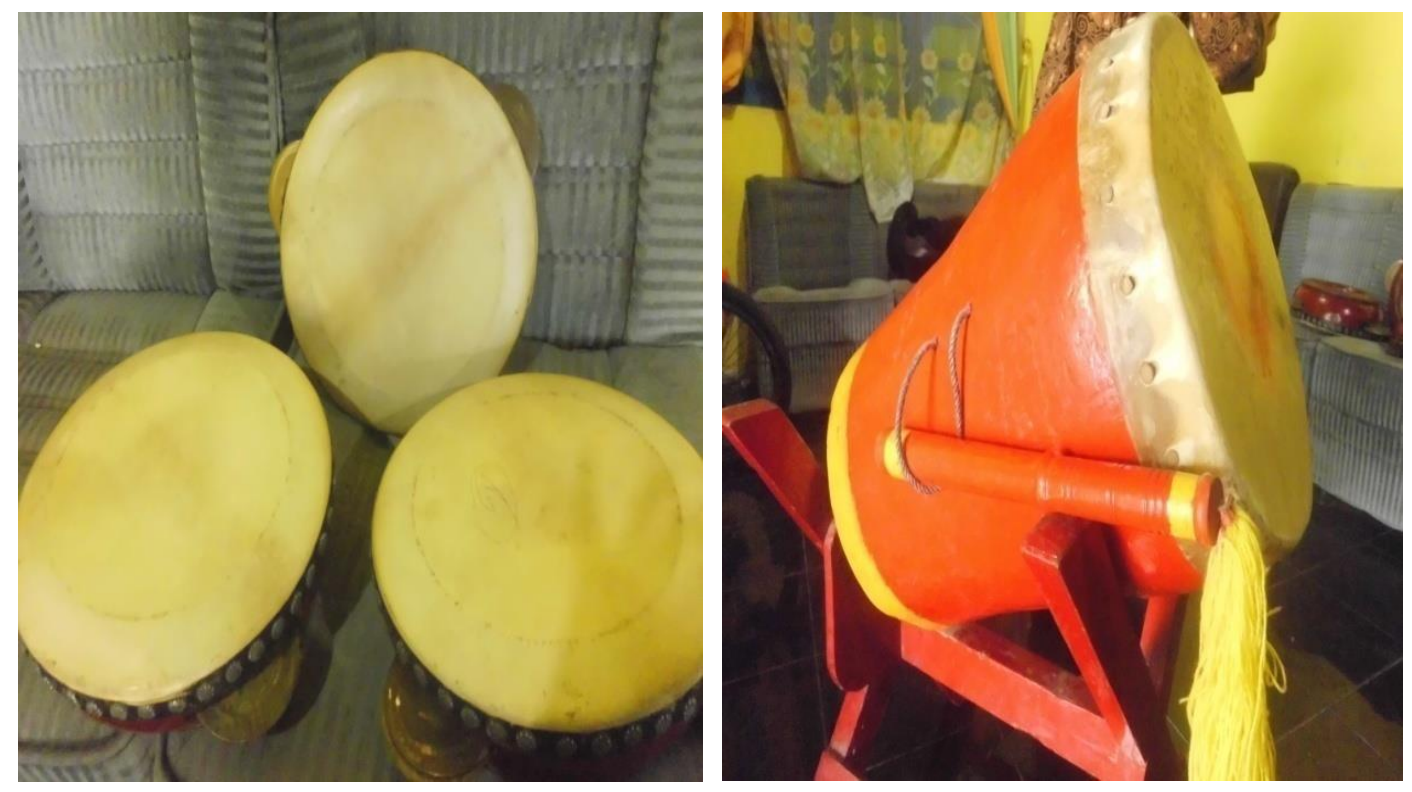

d. Alat musik kesenian tari Badui Dusun Semampi

Sumber: Dokumentasi Pribadi 